\title{
THE EFFECT OF VENTILATION CAPACITY ON WEIGHT LOSSES IN VENTILATED POTATO STORES ${ }^{1}{ }^{2}{ }^{2}$ )
}

\author{
B. G. OPHUIS \\ Institute for Storage and Processing of Agricultural Products, \\ Wageningen, The Netherlands
}

\section{SUMMARY}

The ventilation capacity required for cooling potatoes depends on the climate and is best determined by practical experiments.

Increasing the quantity of air forced through per hour results in little or no increase in evaporation. Hence with a large ventilation capacity shrinkage is not higher than with a small ventilation capacity, especially as in the first case the total number of operating hours may be smaller.

The ventilation capacity recommended for potato stores in the Netherlands is $100 \mathrm{~m}^{3}$ of air per hour per $\mathrm{m}^{3}$ of potatoes. For a storage height of $3.5 \mathrm{~m}$ it is assumed that in delivering the said quantity of air the fan is able to overcome a pressure of $15 \mathrm{~mm}$ water column. Under climatic conditions in the Netherlands it is possible to obtain with this ventilation capacity a storage temperature corresponding to the minimum temperature averaged per 10 days periods. Up to April these temperatures are low enough to prevent sprouting.

In ventilated potato stores the loss of weight of immature harvested potatoes is $3-5 \%$ during the first month subsequent to harvesting and $y_{2}$ to a maximum of $\% \%$ per month in the succeeding period. Ripe lifted potatoes have a weight loss of $1-3 \%$ in the first month and $1 / 2-2 \% \%$ per month during the succeeding period.

\section{INTRODUCTION}

The great bulk of the Dutch potate crop has always been traditionally stored in field clamps. Under Dutch climatic conditions clamping often leads to considerable losses, and it was with a view to improving this situation that intensive research on the subject of potato storage has been carried out in Holland since the second world war. As a result storage with outside air cooling was introduced in practice in 1950 . Since then some 1.400 ventilated storage houses have been built with a total storage capacity of about 400.000 tons.

The main reason which led to the construction of such a large number of storage houses was the improvement in the storage of produce which was thereby effected. Equally important was the saving of labour and improvement in the methods of working. When stored with outside air cooling the tubers remain free of sprouts and are dry and clean after storage. Grading involves less work than in the case of the clamped product, and as a result of indoor storage grading and disposal of produce are independent of the weather. Moreover the various tasks involved have been rendered more agreeable and it is easier to mechanize them than in the case of outdoor clamp storage. The descisive factor in practic is that despite higher initial investment-costs storage in ventilated building is more economical thans clamp storage.

The system is based on the principle of blowing outside air into the store by means of a fan during cold periods in order to cool the potatoes. During warm

1) Received for publication April 20, 1957.

2) Elaborated from the text of a paper read at the International Conference on Farm Buildings, held at Lund, Sweden, from 8th-13th October 1956. 
weather and periods of frost the storage space has to be closed in order to maintain the necessary storage temperature as long as possible. The walls and ceiling of the store must be insulated for the same purpose. The fan serves both for cooling and for rapidly blowing dry wet-lifted potatoes.

To prevent losses during storage the most important requirement is to control temperature and humidity. Whether the desirable conditions are fulfilled by storing with outside air cooling or not depend primarily on the climate, but they are also determined by the method of operating the ventilation system, the insulation of the building and the fan capacity selected. It is the latter point in particular that will be considered in this article and some results of experiments will be published.

\section{Causes of the losses in Weight aNd Methods of PREvention}

The losses in weight that occur during the storage of potatoes are due to the following processes:

a respiration,

b sprouting,

c attack by micro-organisms,

d evaporation.

Respiration and sprouting are processes which arise from the fact that the potato tuber is a living product.

The energy required to maintain the vital processes is supplied by respiration. In this process carbohydrates take up oxygen from the atmosphere and are converted to carbon dioxide and water. The carbon dioxide is relaised in the atmosphere. Hence this process is inevitably accompanied by losses during storage. The intensity of respiration is influenced by temperature and can be measured by determining the amount of carbon dioxide given off. To judge from the figures given in the literature of the subject, it can be calculated that over the entire period of storage the carbonhydrate loss, expressed as a reduction of the original fresh weight, will seldom be more than $1 \%$.

Sprouting always causes loss in weight to a greater or lesser degree. In serious cases the quality may also be affected or there may even be an entire loss. Consequentely when potatoes are stored in bulk the first requirement is to prevent sprouting. The tendency to sprouting may by suppressed by a low storage temperature, but there is no need to store at a very low temperature immediately after harvesting when the tubers have their dormancy period during which there is no sprout development even at higher temperatures. This rest period varies at a constant temperature of about $20^{\circ} \mathrm{C}$ from several weeks to several months according to the variety. Sprouting is retarded when the temperature has decreased below $20^{\circ} \mathrm{C}$. The limit beyond which no further sprouting occurs in a storage period of normal duration (6-8 months) is about $4^{\circ} \mathrm{C}$. In the case of varieties that are very prone to sprout, this limit is rather lower than $4^{\circ} \mathrm{C}$. When potatoes are stored for a very long period until late in the storage season it is also necessary to cool below $4^{\circ} \mathrm{C}$ during the latter months. Experiments conducted at our Institute have shown that (previous to being stored at $4^{\circ} \mathrm{C}$ ) even the most vigorously sprouting varieties remain dormant for 3 months after digging when they are successively stored at $13^{\circ} \mathrm{C}, 10^{\circ} \mathrm{C}$ and $6^{\circ} \mathrm{C}$ during these three months. 
With a program of still lower temperatures than the latter it is possible to prolong storing at $4^{\circ} \mathrm{C}$ for an even longer period.

After the first months the best storage temperature for seed potatoes is $2-4^{\circ} \mathrm{C}$. Prolonged storage of seed potatoes below $2^{\circ} \mathrm{C}$ is less advisable. Since sweetening may occur below $4-5^{\circ} \mathrm{C}$ (in some varieties even below $6^{\circ} \mathrm{C}$ ) lover temperatures should be avoided in the case of ware potatoes. Owing to the risk of sprouting this is impossible when the storage period has to be of some duration, but any sweet taste which may occur as a result of storing at a low temperature usually disappears again when the potatoes are subsequently stored at a higher temperature $\left(10-15^{\circ} \mathrm{C}\right)$ for a week or fortnight before disposal.

Next to sprouting, tuber diseases are the most important cause of losses in weigth. Rotten tubers always mean a total loss. Under certain conditions the infection may spread rapidly during storage. The fault often lies with tubers which were already affected in the field. When potatoes are lifted wet the losses may be very high, particularly if the tubers were damaged during harvesting or blighted, unless they are dried immediately after being stored. Low temperature and storage under dry conditions (no moisture on the surface of the tubers) prevent growth of micro-organisms.

Evaporation causes loss of water from the tubers. Although no solid components are lost, reduction of weight has to be taken seriously into account in the trade. The loss by evaporation is many times greater than that due to respiration. Both are invisible but may be determined as a combined percentage by weighing. When the loss of weight by evaporation is about $10 \%$ or more the tubers feel so soft that their quality is reduced.

The evaporation of water from the tubers is a physical process depending in the first instance on the conditions of the ambient air. In saturated air having the same temperature as the potatoes there is no evaporation, but when potatoes are stored under such conditions there is a risk of condensation and moreover these conditions are not technically feasible for the whole duration of storage.

In consideration of evaporation we cannot merely use the relative humidity of the ambient air as our starting point; the chief factor to be taken into account is the difference in vapour pressure between potatoes and air. An understanding of this is of great importance when produce is ventilated, as will be made clear by an example. In order to reach or maintain the necessary low temperature during storage the potatoes have to be contacted with colder air from time to time. Even if they are ventilated with saturated cold air from outside there will still be evaporation because the saturated air of the warmer potatoes can contain more water than the outside air. The latter air is heated by contact with the potatoes, as a result of which its saturation becomes less than $100 \%$. The potatoes will then lose water vapour to the air having a lower vapour pressure.

It follows from this line of reasoning that to prevent potatoes from drying out when ventilated with cold air the difference in temperature between them and the air forced through should preferably be slight and the relative humidity of this air should preferably be high. The fact that the relative humidity alone is no proper base is shown still more clearly by the fact that when cold potatoes are ventilated with warm, unsaturated air condensation may occur instead of evaporation.

It is not only the condition of the ambient air that influences the degree of evaporation but also the permeability of the skin. Unmature tubers have a 
skin which is very permeable in the first stages after digging. This also applies to skinned tubers. The permeability of the skin depends on the degree of suberisation. As soon as the plant ceases to grow, viz. after the haulm and foliage have died down or have been removed from the tubers, the suberisation process begins. At a temperature of $15^{\circ} \mathrm{C}$ suberisation is rapid; after only a few days there is a very marked decrease in permeability; after a fortnight it practically falls to the minimum. The suberisation process is retarded by low temperatures; at $2^{\circ} \mathrm{C}$ suberisation and healing of wounds are even entirely halted. For this reason green harvested or wounded tubers should always be stored at about $15^{\circ} \mathrm{C}$ for a fortnight prior to low-temperature storage. During this fortnight ventilation with colder or dry air should be avoided.

During sprouting there is a marked increase in evaporation owing to the fact that the permeability of the sprouts is much greater than that of the skin and also because there may be an appreciable increase in evaporating surface.

\section{THE CHOICE OF VENTILATION CAPACITY}

It will be obvious that outside-air cooling is only feasible in climates where the outside temperature drops fairly frequently below the storage temperature required by the product. The choice of ventilation capacity for potato stores, i.e. the quantity of air with which a given quantity of potatoes is ventilated per unit of time, is determined by a number of factors which may be ultimately reduced to two groups, - on the one hand the requirements and properties of the product, on the other the climatic conditions. The following aspects are worthy of particular consideration:

a the required storage temperature The limits within which this should be kept at various times during the storage period were discussed in paragraph 2;

$b$ the respiration heat and the insulation of the building A certain amount of heat is liberated in the respiration process. It can be calculated from the intensity of respiration at low storage temperatures that this heat is sufficient to heat the product ${ }_{10}^{\circ} \mathrm{C}$ in twenty-four hours. If the respiration heat is not removed by ventilation or in some other way it is, in fact, noticed that there is a rise of temperature of $1_{4}^{1 \circ} \mathrm{C}$ a day. Thus in four days the temperature may rise $1^{\circ} \mathrm{C}$. Assuming that $4^{\circ} \mathrm{C}$ is the maximum and $2^{\circ} \mathrm{C}$ the minimum storage temperature, this means that \pm 8 days is the longest period during which potatoes can remain without cooling. Moreover, should heat enter the building from outside (as a result of "draught" or conduction through the walls) cooling is required even earlier. Where the climate scarcely permits ventilation this penetration of heat should accordingly be counteracted as much as possible. In the first place the storage space should be properly closed so that no warm outside air is able to enter as a result of natural draught. Secondly the walls should be insulating so that the rise in temperature of the potatoes is mainly due to respiration and only to a very reduced part to conductive heat through walls and ceiling. The degree of insulation required will depend on the temperature and the duration of the periods without cooling. For climatic conditions in the Netherlands the minimum insulation value is $0.5-0.6 \mathrm{kcal} / \mathrm{m}^{2} \mathrm{~h}^{\circ}$ C. Such a degree of insulation affords also sufficient protection against frost such as occurs in Holland (1). 
Should frequent ventilation be impossible it is advisable to cool the potatoes to $+1^{\circ} \mathrm{C}$ or even to $+0.5^{\circ} \mathrm{C}$ during a favourable cold period. In this way a greater "cold reserve" is formed which permits a longer waiting period until there is again an opportunity to ventilate. Provided they are not kept up for weeks or months in succession temperatures of less than $2^{\circ} \mathrm{C}$ cause no harm to the potatoes. In the case of ware potatoes it will however be necessary to take care that the tubers are stored warm for a fortnight before consumption. The sweet taste may disappear by this treatment.

To sum up we can say that with a storage temperature of $4^{\circ} \mathrm{C}$, which is the maximum for winter and spring storage, warm periods lasting longer than about 10 days cannot be bridged over without cooling. If the outside temperature does not fall below $4^{\circ} \mathrm{C}$ more frequently than once every 10 days the climate is unsuitable for cooling with outside air. During periods of frost the maximum period to be bridged over may be longer because a part of the respiration heat escapes outside via the walls of the storage house. In this case a period of about a fortnight may be overbridged without ventilation with cold air.

Since potatoes consume oxygen a slight replenishment of air is always called for, even if it is impossible to ventilate. As a rule no special measures are required for this purpose as in practice a storage place can never be hermetically sealed. Moreover the opening and closing of the doors when the store is entered for the routine check is often sufficient to supply the necessary gas exchange. This slight replenishment of air has not much effect on the temperature in the store either during frost or warm periods.

$c$ the outside air temperature Temperatures of less than $0^{\circ} \mathrm{C}$ are unsuitable when the outside air is brought into direct contact with the potatoes. It is, however, possible to ventilate during frost by mixing the outside air with air from the store until it is just above freezing-point. Unless this has to be done only occasionally it requires a special installation working automatically by means of thermostats and servomotors. Such an installation is fairly complicated and expensive. In an alternative method of ventilating during frost the air is not forced through the product but led around the potato heap by means of double walls and partitions (shell-cooling). In this way the product is cooled indirectly. This system is also more expensive than forcing air through the heap.

We saw under $3 \mathrm{~b}$ that even during frost it is impossible to bridge over a period lasting longer than about a fortnight without cooling. Consequently ventilation during periods of frost is required in climates in which the outside temperature remains continually below $0^{\circ} \mathrm{C}$ for several weeks or months. The system of shell-cooling, or air-mixing, is therefore employed, for example, in the northern states of the U.S.A. and Canada. In shell-cooling heat is transmitted from the potato heap in a much less effective way than when the potatoes are in direct contact with forced air. Consequently this system is unsuitable outside areas with a prolonged, severe winter.

In the more temperate climate of west and central Europe and southern Scandinavia it never freezes continually all through the winter. Periods of frost alternate with days of thaw and it seldom happens that during a prolonged period of frost there is not even one day of sunshine in two or three weeks when the mercury rises above $0^{\circ} \mathrm{C}$ for a few hours. Hence in this 
climatic zone ventilation with frostly air is generally not necessary. Should it nevertheless be desirable during the odd day, air-mixing may be applied in a simple way by means of the internal circulation equipment available. The desired degree of air-mixing may then be obtained by ventilating internally and opening the air inlet and outlet as required.

The degree of cooling required during ventilation depends on the difference in temperature between the potatoes and the outside air, the duration of the ventilation and the ventilation capacity. There are also some material properties that must be taken into account, such as the specific heat of air and potatoes, the heat transfer coefficient of air on potatoes, and the surface area per $\mathrm{m}^{3}$ of potatoes taking part in the heat transmission. Ignoring these magnitudes, the degree of cooling is directly proportional to the difference in temperature, the duration of the ventilation, and the quantity of air forced through per unit of time. Hence with the same difference in temperature, doubling the ventilation capacity results in a halving of the cooling time. The temperature at which it is possible to ventilate, and the frequency and regularity with which suitable ventilating periods occur is determined by climatic conditions.

If the outside air is forced directly through the product the eligible temperatures are restricted to the range of $0-4^{\circ} \mathrm{C}$ with the exception of the first few months subsequent to harvesting. Thus the difference in temperature is not great. One could remark that it should also be possible to ventilate in temperate climates at temperatures of less than $0^{\circ} \mathrm{C}$. During night-frost it would then be possible to benefit from a greater difference in temperature and a longer duration of time, with the result that a smaller ventilation capacity would be sufficient. However the ventilation capacity should not be based on the months in which low temperatures and night-frost are a frequent occurrence, but on the months with only a few cold nights in which the temperature seldom falls to $0^{\circ} \mathrm{C}$. During these months the greatest possible cooling effect should be aimed at whenever there is a favourable opportunity. During a number of cold hours in the night or morning a sufficient cooling can only be achieved by means of a high ventilation capacity.

$d$ the storage height In the type of storage houses built in Holland for bulk storage of potatoes $(2,3)$ the air-distributing system is arranged in the floor. During ventilation the air is forced upward through the heap from below. In view of the risk of damaging the potatoes by pressure, a storage height of 3 metres is about the maximum. The storage height is also limited by the fact, that the entire bulk of potatoes from the bottom to the top must be cooled down within a certain time. Since the cold air is injected from the bottom it is here that the potatoes will be first subject to cooling. There is a gradual upward transmission of the drop in temperature so that the top layers take longer to reach the right temperature than do the bottom ones. The ventilation capacity should accordingly be such that even during short ventilation periods in the least favourable months the potatoes are cooled as far as possible to the inside of the top layers.

Hitherto no exact figures were available regarding the process of cooling in a heap of potatoes. Some years ago Businger (4) formulated a general theory on the cooling or heating of dumped produce. This theory has been confirmed by experiments recently conducted at our Institute, and we were able to obtain 
from the measurements the numerical values required for making calculations (5). This question will be referred to again in paragraph 4 .

$e$ shrinkage It was first feared that increasing the ventilation capacity would result in an increase in the amount of water lost by the tubers. Experiments made in successive years showed that increasing the ventilation capacity to two or three times its normal value did not result in any increase in evaporation. The summarized results of a special experiment on this subject will be given in paragraph 5 .

It follows from the above considerations that it is difficult to determine the proper ventilation capacity by calculation alone. It would, for example, be necessary to know the exact duration, frequency and regularity of the temperatures favourable for ventilation, but these data are not readily available. Consequently in Holland we have determined experimentally the ventilation capacity with which good results were obtained. In these experiments the product was, of course, assessed at the end of the storage period. The storage temperatures were also accurately recorded. On the basis of these experiments the ventilation capacity advised during the first few years was $70 \mathrm{~m}^{3}$ per hour per $\mathrm{m}^{3}$ of potatoes (this corresponds to $11 \mathrm{~m}^{3}$ per $100 \mathrm{~kg}$ per hour). The temperature observations brought to light a surprising fact (1). It was found that under the climatic conditions prevailing in Holland, except during the periods of frost, the trend of the mean storage temperature obtained with the said ventilation capacity practically coincided with the mean minimum outside temperature per ten days period. This relationship was constantly found, so that with the aid of meteorological data it is possible to deduce from it what storage temperatures are possible in the Dutch climate during the various months (see table 1).

Table 1 Mean temperatures in Holland in $0^{\circ} \mathrm{C} 1$ )

\begin{tabular}{|c|c|c|c|c|c|c|c|c|c|c|c|c|}
\hline & $\underline{\Xi}$ & $\sum^{\infty 0}$ & 莒 & ப் & 客 & $\stackrel{\dot{D}}{\stackrel{D}{0}}$ & $\stackrel{\Xi}{\Xi}$ & $\frac{\ddot{0}}{0}$ & 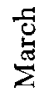 & $\overrightarrow{\bar{z}}$ & $\stackrel{\Xi}{\Sigma}$ & $\stackrel{\Xi}{\Xi}$ \\
\hline Mean temp. & 18.2 & 17.7 & 15.0 & 10.4 & 5.8 & 3.2 & 2.6 & 3.0 & 5.6 & 8.9 & 13.8 & 16.4 \\
\hline Mean min. temp. & 12.7 & 12.4 & 10.1 & 6.6 & 3.1 & 0.8 & 0.0 & 0.0 & 1.7 & 4.0 & 7.8 & 10.5 \\
\hline Mean max. temp. & 21.4 & 21.1 & 18.6 & 13.5 & 8.4 & 5.3 & 4.8 & 5.6 & 8.8 & 12.2 & 17.3 & 19.8 \\
\hline
\end{tabular}

1) The figures shown in Table 1 are averages taken over a long series of years and apply to the whole of the Netherlands.

According to the figures for the mean minimum temperatures, in Holland it is possible to cool to about $13^{\circ} \mathrm{C}$ in Puly and August, to $10^{\circ} \mathrm{C}$ in September, to an average of $7^{\circ} \mathrm{C}$ in October, and to $4^{\circ} \mathrm{C}$ or lower from November to April. With this program of storage temperatures, potatoes can be kept sproutless up to the end of April (cf. paragraph 2). The outside temperatures may, of course, deviate from this mean year to year and from place to place. What this means for the storage temperatures can be seen in a climatogram compiled in respect of 6 locations in the Netherlands for the years 1920 to 1950 (1). 
Since DE JoNG started on the investigation in 1947 (6) the experiments with outside air cooling have been continued in each succeeding year. Both these experiments and practical experience prove that if the system is properly operated it is, in fact, possible in most years to store potatoes up to April without any appreciable sprouting. When the ventilation capacities were greater than $70 \mathrm{~m}^{3} / \mathrm{m}^{3} \mathrm{~h}$, it was only possible to effect a slight reduction in the average storage temperature throughout the season. But it was precisely during the periods unfavourable for ventilation that a difference could be observed. The differences in sprouting, as evidenced in Table 2, are consequently to be attributed to the fact that it is particularly during critical periods that a lower temperature can be reached with the greater ventilation capacity.

Table 2 The effect of the ventilation capacity on sprouting and total loss of weight.

\begin{tabular}{|c|c|c|c|c|c|c|c|}
\hline \multirow{3}{*}{ Season } & \multirow{3}{*}{ Variety } & \multicolumn{6}{|c|}{ Ventilation capacity } \\
\hline & & \multicolumn{2}{|c|}{ ca. $70 \mathrm{~m}^{3} / \mathrm{m}^{3} \mathrm{~h}$. } & \multicolumn{2}{|c|}{ ca. $140 \mathrm{~m}^{3} / \mathrm{m}^{3} \mathrm{~h}$. } & \multicolumn{2}{|c|}{ ca. $210 \mathrm{~m}^{3} / \mathrm{m}^{3} \mathrm{~h}$} \\
\hline & & $\begin{array}{l}\text { total } \\
\text { loss } \%\end{array}$ & $\begin{array}{l}\text { sprout- } \\
\text { ing \% }\end{array}$ & $\begin{array}{c}\text { total } \\
\text { loss } \%\end{array}$ & $\begin{array}{l}\text { sprout- } \\
\text { ing } \%\end{array}$ & $\begin{array}{l}\text { total } \\
\text { loss } \%\end{array}$ & $\begin{array}{l}\text { sprout- } \\
\text { ing \% }\end{array}$ \\
\hline $1953 / 54$ & Eersteling & 3.20 & 0.54 & 2.82 & 0.41 & - & - \\
\hline $1954 / 55$ & Bintje & 4.01 & 0.16 & 3.95 & 0.04 & - & - \\
\hline $1955 / 56$ & Bintje & 5.59 & 0.48 & 5.51 & 0.15 & - & - \\
\hline $1956 / 57$ & Bintje & 1.72 & 0.37 & 1.64 & 0.10 & 1.62 & 0.03 \\
\hline
\end{tabular}

The total loss figures shown in the table vary considerably for the different seasons. This is owing to the great difference between the various storage periods and the fact that in one year the experiment was begun immediately after harvesting and in another year some weeks afterwards. The figures are higher in the first instance because it is the period soon after harvesting in which the losses in weight are very considerable.

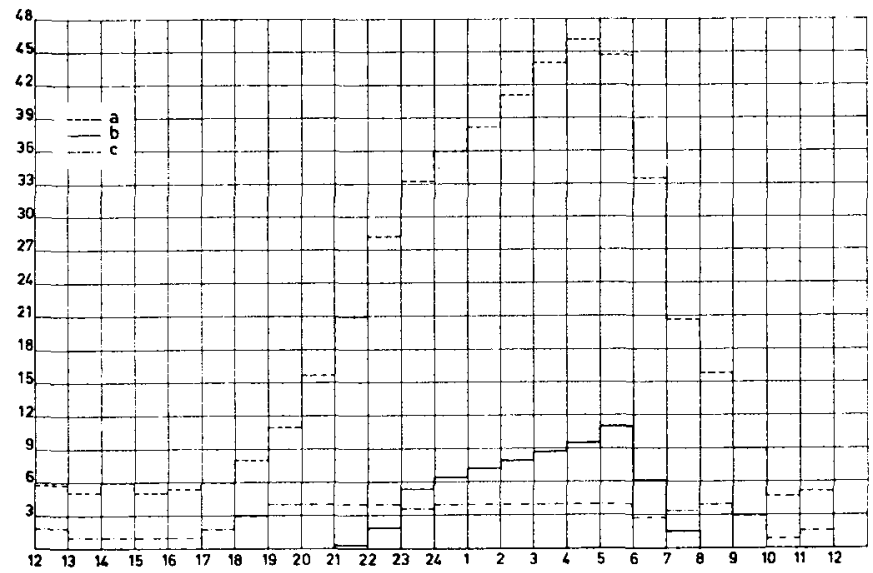

Fig. 1 Distribution of ventilation hours over the hours of the Day.

$\mathrm{a}=$ over the whole storage season (from $7 / 7 /{ }^{\prime} 53$ till $11 / 3 /{ }^{\prime} 54$ ) total time of ventilation 490 hours; daily average 2 hours

$\mathrm{b}=$ over September

$\mathrm{c}=$ over January. 
It was also observed that with a greater ventilation capacity there was a reduction in the total number of hours during which the ventilator operated. Doubling the ventilation capacity did not, however, halve the total operating period as there was only a difference in the operating time during periods with a maximum opportunity of ventilating. Fig. 1 is a frequency diagram showing the distribution of the operating hours over the hours of the day during the season 1953-54. The ventilation capacity was $70 \mathrm{~m}^{3} / \mathrm{m}^{3} \mathrm{~h}$. It can be seen from this, that ventilation was chiefly applied during the night and early morning. During September ventilation was even limited to nighttime only, and in January there were also favourable temperatures during daylight.

Since 1954 the ventilation capacity of $70 \mathrm{~m}^{3}$ recommended by our Institute has been increased to $100 \mathrm{~m}^{3}$ per $\mathrm{m}^{3}$ of potatoes per hour. For a storage height of $3.5 \mathrm{~m}$ this is equal to $350 \mathrm{~m}^{3}$ of air per $\mathrm{m}^{2}$ of floor space per hour. Measurements made by us with clean potatoes show (cf. Fig. 2) that with

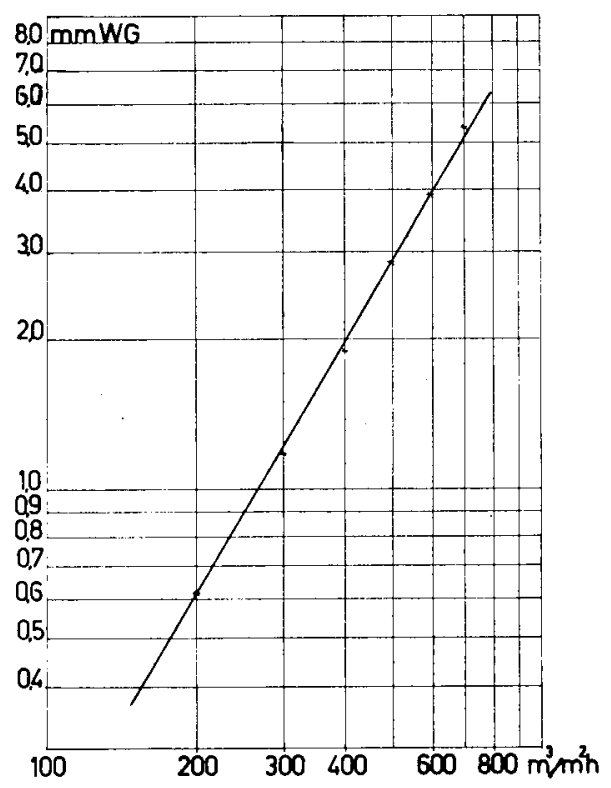

Frg. 2 Resistance to airflow of a 1 M thizk layer of potatoes.

this air velocity a layer of potatoes of $1 \mathrm{~m}$ thick has a resistance of $1.6 \mathrm{~mm}$ WG. As it was also discovered that the air resistance increases in proportion to the storage height, the loss of pressure for a stack of potatoes $3.5 \mathrm{~m}$ high is consequently $5.6 \mathrm{~mm} \mathrm{W.G.} \mathrm{But} \mathrm{in} \mathrm{the} \mathrm{case} \mathrm{of} \mathrm{dirty} \mathrm{potatoes} \mathrm{actual} \mathrm{measure-}$ ments showed that the resistance is higher. The air is also subject to resistance in the ducts of the ventilation system. Hence the rule generally adopted is that for a ventilation capacity of $100 \mathrm{~m}^{3} / \mathrm{m}^{3} \mathrm{~h}$ the fan should be capable of overcoming a resistance of $15 \mathrm{~mm} \mathrm{W.G.}$

4 The TEMPERATURE IN THE HEAP DURING VENTILATION

As indicated above under $3 \mathrm{~d}$ the cooling during ventilation is a function of both the time and the height in the stack. In addition, the temperature 
depends on the ventilation capacity. In order to make a correct choice of the latter and to operate the ventilation correctly it is very important to have a proper understanding of the cooling process.

From theoretical considerations Businger (4) arrived at a computational method for the heating or cooling of stacked products by ventilation with air. It is assumed that in the initial state the stack is at the same temperature in all layers and that ventilation is applied with air of a constant temperature during the entire heating or cooling process. It is also assumed that the product gives off no moisture to the air flow. In solving the differential equations denoting the heat-exchange between air and product Businger introduced dimensionless variables for temperature, height of the stack and time. The temperature of the product may be written in the following form:

$$
\vartheta=\frac{T_{1}-T_{2(O)}}{T_{1(O)}-T_{2(O)}}
$$

In this formula $T_{1}$ denotes the temperature of the product during ventilation, $T_{1(O)}$ the initial temperature of the product and $T_{2(O)}$ the temperature of the air that is blown in the heap. For the height $(x)$ Busingen substitutes $\xi==\frac{a O x}{C_{1}} V$ and for the time: $\tau==\frac{a(t)}{C_{2}}$.

In this formula

$$
\begin{aligned}
& \alpha=\text { heat transfer coefficient }\left(\mathrm{kcal} / \mathrm{m}^{2} \mathrm{~h}^{\circ} \mathrm{C}\right) \\
& O=\text { surface area of the potatoes }\left(\mathrm{m}^{2} / \mathrm{m}^{3}\right) . \\
& t=\text { time (hrs) } \\
& x=\text { height in the stack }(\mathrm{m}) \\
& C_{1}=\text { heat capacity of the air }\left(\mathrm{kcal} / \mathrm{m}^{3}{ }^{\circ} \mathrm{C}\right) \\
& C_{2}=\text { " }=\text { of the product }\left(\mathrm{kcal} / \mathrm{m}^{3}{ }^{\circ} \mathrm{C}\right) \\
& v=\text { ventilation capacity }\left(\mathrm{m}^{3} / \mathrm{m}^{2} \mathrm{~h}\right) .
\end{aligned}
$$

The relation between $\vartheta, \xi$, and $\tau$ has been worked out graphically by Businger.

If all values are known, Businger's graph can be used for calculations of the heating or cooling of a stack of potatoes. $C_{1}, C_{2}$ and $v$ are readily determined, or a reasonable estimate can be made of them. If it is assumed that the potatoes are spheres with a diameter of $40 \mathrm{~mm}$ and that all spheres lie closely packed, it can be calculated that the surface area $O$ is approximately $120 \mathrm{~m}^{2} / \mathrm{m}^{3}$. We estimated the $\alpha$ from Jürges' formula $\alpha=5 \times 3.4 w$, in which $w$ should be taken as representing the air velocity between the tubers in $\mathrm{m} / \mathrm{sec}$. For a pore volume of $33 \%$ is $w=\frac{3 \times v}{3600} \mathrm{~m} / \mathrm{sec}$. We were able to check the estimated values of $\alpha$ and $O$ by measuring the temperature on various heights in the heap during ventilation with warm air. The measurements were made with clean potatoes having a mean diameter of $40 \mathrm{~mm}$. Inserting the said estimated values for $\alpha$ and $O$ gave a substantially complete agreement between the calculated and the measured trend (5). On the basis of this, using BusingER's equations, we have shown graphicially in Fig. 3 the temperature trend during cooling for the ventilation capacity of $350 \mathrm{~m}^{3} / \mathrm{m}^{2} \mathrm{~h}$, which is customary in Holland. In making the calculation the following values were inserted: 


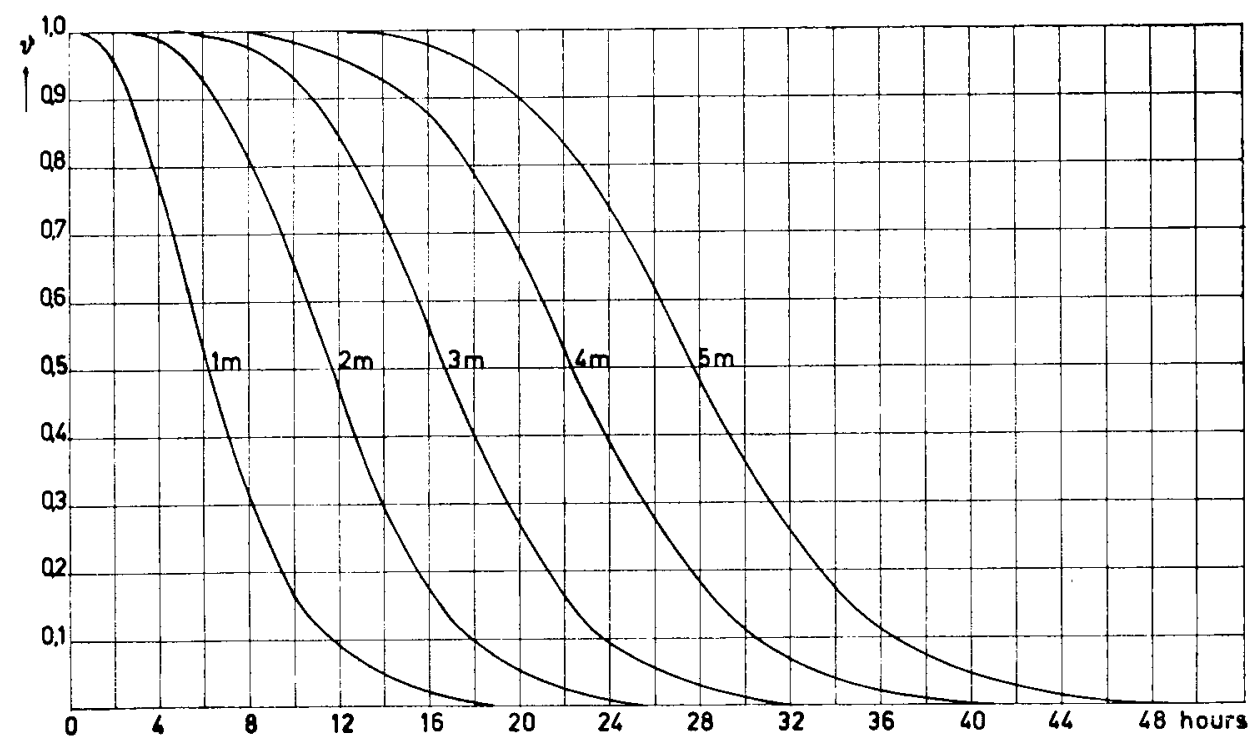

Fig. 3 Course of temperature at various heights in a STACK of potatoes when venTILATED WITH COLD AIR OF CONSTANT TEMPERATURe AT A RATE OF $350 \mathrm{M}^{3} / \mathrm{M}^{2} \mathrm{H}$. $\vartheta=\frac{T_{1}-T_{2(O)}}{T_{1(O)}-T_{2(O)}}$ (see text).

$\alpha=5+3.4 \times \frac{3 \times 0}{3600}=6 \mathrm{kcal} / \mathrm{m}^{2} \mathrm{~h}{ }^{\circ} \mathrm{C}$.

$O=120 \mathrm{~m}^{2} / \mathrm{m}^{3}$ (applies to round potatoes with a mean diameter of $40 \mathrm{~mm}$ in dense packing).

$C_{1}=0.3 \mathrm{kcal} / \mathrm{m}^{3}{ }^{\circ} \mathrm{C}$.

$C_{2}=575 \mathrm{kcal} / \mathrm{m}^{3}{ }^{\circ} \mathrm{C}$ (assuming the potatoes having a weight by volume of $700 \mathrm{~kg} / \mathrm{m}^{3}$ and a specific heat of $0.82 \mathrm{kcal} / \mathrm{kg}{ }^{\circ} \mathrm{C}$ ).

$v=350 \mathrm{~m}^{3} / \mathrm{m}^{2} \mathrm{~h}$.

From this graph we can read the cooling trend at various heights in the stack of potatoes. When $\vartheta=0.5$ this means that the product has cooled to such an extent that the original difference in temperature between the product and the forced air has been halved. The corresponding time is termed the half-value time. When $\vartheta=0.1$ the corresponding time is said to be the $1 / 10$-value time. This will be made clear by an example. If before ventilation is begun the potatoes had a temperature of say $8^{\circ} \mathrm{C}$ over the entire heap and the temperature of the outside air remains constant at say $2^{\circ} \mathrm{C}$ during ventilation, then $\theta=0.5$ denotes that the temperature of the potatoes has fallen by $0.5(8-2)=3^{\circ} \mathrm{C}$, viz. they have cooled to $5^{\circ} \mathrm{C}$. We can see from the graph that with $350 \mathrm{~m}^{3} / \mathrm{m}^{2} \mathrm{~h}$ the point $\vartheta=0.5$ at $1 \mathrm{~m}$ height is reached after $6 \frac{1}{2}$ hours' ventilation. At a height of $3 \mathrm{~m}$ however the half-value time is nearly 17 hours. The $1 / 10$-value time (i.e. in the example of cooling to $2.6^{\circ} \mathrm{C}$ ) is not reached at 1 and $3 \mathrm{~m}$ until after 12 and 24 hours of ventilation respectively. This example demonstrates clearly that even with a ventilation capacity of $350 \mathrm{~m}^{3} / \mathrm{m}^{2} \mathrm{~h}$ (a level which is scarcely ever maintained abroad) it is necessary to ventilate for several hours to obtain an adequate cooling in the top of the stack as well. 
Increasing the ventilation capacity leads to a reduction in the cooling time. We calculated (5) that when $\vartheta=0.1$ the relation between cooling time and ventilation capacity can be represented by the formula $t=\frac{40250}{5400 \times 3 v}+$ $2130 \frac{x}{v}$ This is shown graphically in Fig. 4. It can be seen from this that at $350 \mathrm{~m}^{3} / \mathrm{m}^{2} \mathrm{~h}$ the $1 / 10$-value time at a height of $3 \mathrm{~m}$ in the stack is 24 hours. According to the graph, by doubling the ventilation capacity the $1 / 10$ value time at this height is reduced to $14 \%$ hours.

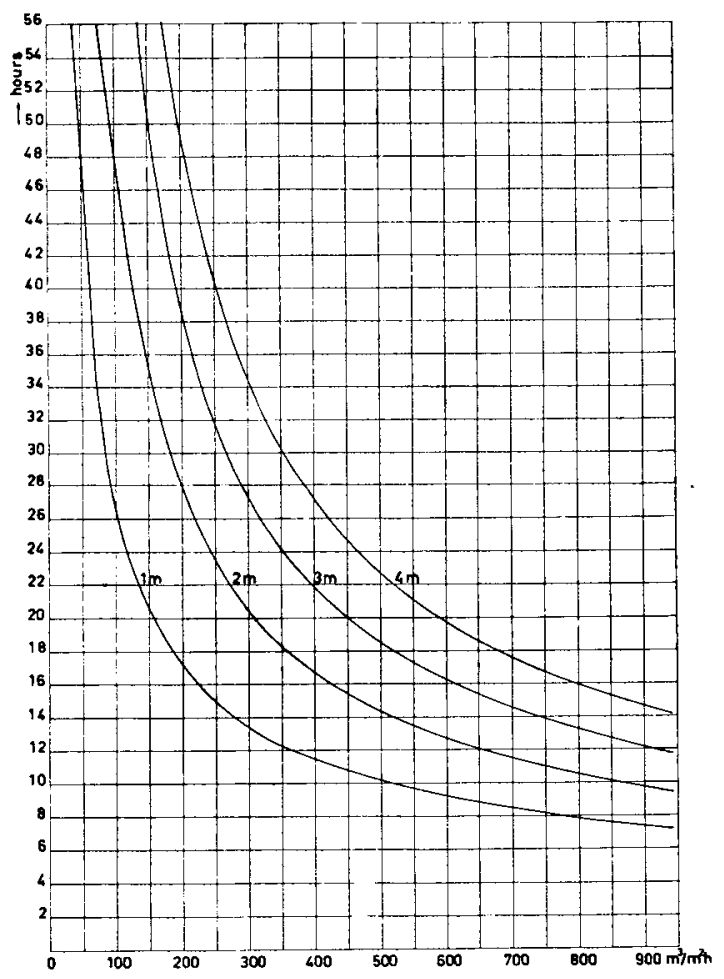

Fig. 4 Influence of ventilation CaPaCity on COOLING time For $\theta=0.1$ and various HEIGHTS IN THE HEAP.

It might be supposed that by regularly reversing the direction of the air current it might be possible to effect a more uniform and rapid cooling of the mass of potatoes, but the reverse is the case. In fact, as soon as the air current is reversed after the potatoes have been ventilated for some time from the bottom upwards, the air with the heat absorbed in the top will again heat the potatoes in the bottom layers. Hence regularly reversing the air current amounts to shifting heat in the mass from the top to the bottom and vice versa, and the cooling period is appreciably extended as a result.

We did, however, find that when the storage height is considerable and ventilation is applied from above to below, over the whole storage season the mean temperature in the stack is more uniformly distributed than when the air is forced through the product from the bottom to the top according to 
the general practice. This difference is to be explained by the fact that in the first case when ventilation cannot be applied the natural convection in the stack (cold air falls) causes a certain levelling of temperature.

\section{The efFect of the ventilation on the LOSS OF WATER}

In connection with what has already been said in paragraph 4 , the process of evaporation of water from the tubers may be represented as diffusion of water vapour through a membrane.

The formula for this process is :

$$
Q=k F\left(p_{1}-p_{2}\right) t
$$

in which

$Q=$ the amount of water vapour moving from one side of the membrane to the other $(\mathrm{kg})$,

$F=$ surface area of the membrane $\left(\mathrm{m}^{2}\right)$,

$p_{1}$ and $p_{2}=$ the water vapour pressure on each side of the membrane respectively ( $\mathrm{mm} \mathrm{Hg}$ or $\mathrm{kg} / \mathrm{m}^{2}$ or $\mathrm{kg} / \mathrm{cm}^{2}$ ),

$t=$ time (hours),

$k=$ proportionality factor, depending on the water vapour permeability of the membrane. $\mathrm{k}$ is termed the water vapour transmission coefficient. expressed in $\mathrm{kg} / \mathrm{m}^{2} \mathrm{~h}$ per unit of difference in vapour pressure.

With regard to potato tubers, the skin may be regarded as the membrane of which $F$ denotes the surface area and $k$ the permeability for water vapour. $p_{1}$ is the water vapour pressure in the tuber. It may be assumed that this is equal to the saturated vapour pressure of water at the same temperature as the potato tuber has. $p_{2}$ is the vapour pressure of the air surrounding the tuber and is therefore dependent on the temperature and the relative humidity of this air.

When potatoes come into contact with cold air $p_{2}$ is always lower than $p_{1}$. Evaporation will even occur when ventilating with cold outside air having a relative humidity of $100 \%$, since when it passes the warmer mass of potatoes the temperature of the air rises and its saturated vapour pressure also increases as a result. Consequently evaporation cannot be avoided under any circumstances when cooling potatoes with cold air, and its makes no difference whether cold outside air is used for the cooling or artificially cooled air. In the first instance the moisture given off is entrained outside by the air flowing through, and in the second instance it is separated from the air in the cooler.

The greater the difference in temperature between the potatoes and the cold air and the lower the relative humidity at which this air is forced in, the greater is $p_{1}-p_{2}$ and hence the greater the evaporation. The formula shows that the amount evaporated depends on the duration of time in which the vapour pressure difference prevails. Thus the total number of ventilation hours is an important factor.

It has been assumed by some that an enlargement of the ventilation capacity would result in an increase in evaporation. No reliable evidence of this has been obtained in experiments conducted on a practical scale during past 
years. In order to study this question in detail, an experiment was carried out last year in which samples of $100 \mathrm{~kg}$ of potatoes were stored in containers which could be weighed at any desired time. The experiment was conducted with immature harvested potatoes (Bintje variety) which were placed in the containers immediately after lifting. The containers were connected to a common ventilating duct so that the periods and duration of ventilation were the same for all. Except in the case of container e which was not ventilated during the first 20 days, forced ventilation with cold outside air had begun immediately after lifting. The fan was only operated when the outside air was colder than the potatoes in the containers. Container $d$ was ventilated with air saturated with steam. For container $b$ the ventilation capacity was $600 \mathrm{~m}^{3} / \mathrm{m}^{2} \mathrm{~h}$, for the others $300 \mathrm{~m}^{3} / \mathrm{m}^{2} \mathrm{~h}$. The potatoes in container a were severely skinned during filling. Fig. 5 shows the loss in weight during the first 6 weeks. In all objects the weight loss during the first few days, when the skin is still incompletely suberised, is much greater than later on.

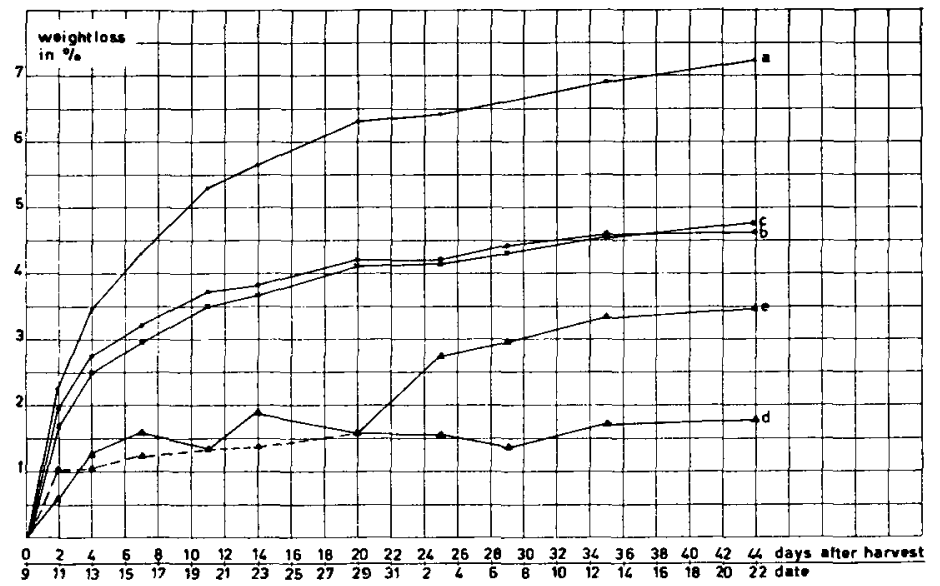

Fig. 5 Loss IN WEIGHT OF GREen HARVESTED POTATOES DURING FIRST SIX WEEkS AFTER haRVEST. The potatoes Were STORED IN CONTAINERS COOLED BY Ventilation With COLD OUTSWE AIR.

$a=$ tubers skinned before storage ventilation capacity $300 \mathrm{~m}^{3} / \mathrm{m}^{2} \mathrm{~h}$

$\mathrm{b}=$ ventilation capacity $300 \mathrm{~m}^{3} / \mathrm{m}^{2} \mathrm{~h}$, tubers not skinned

$\mathrm{c}=\quad " \quad, 600 \mathrm{~m}^{3} / \mathrm{m}^{2} \mathrm{~h}, \quad, \quad, \quad "$

$\mathrm{d}=\quad " \quad$ " $\quad 300 \mathrm{~m}^{3} / \mathrm{m}^{2} \mathrm{~h}, \quad " \quad, \quad$ " $\mathrm{e}=$ putting into the container.

When no ventilation is applied during the first weeks (container e) the loss of weight is much lower, although a considerable rise can be noticed as soon as ventilation has begun. The humidity of the air has a marked effect, as can be seen by comparing $d$ with $b$ or $c$. In the case of the skinned tubers the loss of weight is very high (see $a$ ), but it is noticeable (cf. $b$ and $c$ ) that the ventilation capacity has scarcely any effect.

In table 3 the mean loss of weight of the containers per twenty-four hours is calculated for 3 periods of the storage season: 
Table 3 Mean loss of weight ${ }^{1}$ ) of green harvested potatoes per twenty-four hours (in percentages).

\begin{tabular}{|c|c|c|c|c|c|}
\hline $\begin{array}{l}\text { Period after } \\
\text { harvesting }\end{array}$ & $\begin{array}{c}\text { a } \\
\text { Skinned } \\
300 \mathrm{~m}^{3} / \mathrm{m}^{2} \mathrm{~h}\end{array}$ & $\frac{b}{300 \mathrm{~m}^{3} / \mathrm{m}^{2} \mathrm{~h}}$ & 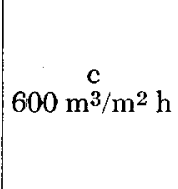 & $\begin{array}{c}\mathrm{d} \\
\text { Air satur } \\
\text { ated with } \\
\text { steam } \\
300 \mathrm{~m}^{3} / \mathrm{m}^{2} \mathrm{~h}\end{array}$ & $\begin{array}{c}\mathrm{e} \\
\text { Ventilation } \\
\text { started } 3 \\
\text { weeks after } \\
\text { harvesting } \\
300 \mathrm{~m}^{3} / \mathrm{m}^{2} \mathrm{~h}\end{array}$ \\
\hline $1-10$ days .. & 0.53 & 0.35 & 0.37 & 0.14 & 0.14 \\
\hline 10-20 days.. & 0.11 & 0.07 & 0.06 & 0.00 & 0.14 \\
\hline 20 days -5 months & 0.03 & 0.02 & 0.02 & 0.01 & 0.03 \\
\hline
\end{tabular}

1) The loss of weight is solely in respect of respiration and evaporation. There was still no sprouting after 5 months.

It must be concluded from these figures that an increase in the ventilation capacity is not accompanied by more intense evaporation. This is logical, when it is borne in mind that the permeability of the skin remains the same whether the ventilation capacity is great or small and that the amount of air diffusing through the skin scarcely affects the vapour pressure of the air forced through even at the lower ventilation capacity.

The following practical figures were found by us for the loss of weight by respiration and evaporation conjointly during air-cooled storage (7).

For immature harvested potatoes : 4-6\% during the first month subsequent to harvesting, $1 / 2$ to a maximum of $\% \frac{3}{\%}$ per month during the succeeding period;

For ripe harvested potatoes (the skin having already been suberised in the ground) : $1-3 \%$ during the first month subsequent to harvesting, afterwards $\%$ to $\%$ per month.

These figures relate to potatoes without sprouting. In the experiment with containers, discussed in this paragraph, after 5 months container b was placed for some time in a room with a higher temperature to allow the potatoes to sprout. When the tubers had sprouts of 1 to $2 \mathrm{~cm}$ the container was again ventilated. The mean loss of weight was then $0.06 \%$ per twenty-four hours, or $1.8 \%$ per month.

\section{REFERENCES}

1 OpHüs, B. G.: Isolatie en luchttechnische inrichting van aardappelbewaarplaatsen. Landbouwk. Tijdschr. 63 (1951) 509-522.

2 - - : Moderne luchtgekoelde aardappelbewaarplaatsen. Landb. Mech. 7 (1956) $72-82$.

3 - - : Ontwikkelingen bij de inrichting van aardappelbewaarplaatsen en het gebruik ervan voor andere produkten. Landbouwk. Tijdschr. 69 (1957) 54-70.

4 BUSINGER, J. A. : Luchtbehandeling van produkten in gestorte toestand. Verwarming en Ventilatie 11 (1954) 31-35.

5 Ophuis, B. G. en J. C. Hesen: De invloed van de ventilatiecapaciteit op het temperatuurverloop in een aardappelhoop. Publikatie van het Inst. voor Bewaring en Verwerking van Landbouwprodukten 1957 (nog niet verschenen).

6 Jong, W. H. DE: Bewaring van aardappelen in gebouwen. Landbouwk. Tiidschr. 61 (1949) 610-627.

7 Ophuis, B. G. en D. HoFstRA: Gewichtsverliezen bij de bewaring van pootaardappelen in luchtgekoelde bewaarplaatsen. Meded. N.A.K. 13 (1956) 48-50. 